\title{
Non-Destructive Evaluation Method Based On Dynamic Invariant Stress Resultants
}

\author{
Junchi Zhang ${ }^{1}$, Luciana R. Barroso ${ }^{1}$, Stefan Hurlebaus ${ }^{1, a}$, and Norris Stubbs ${ }^{1}$ \\ ${ }^{1}$ Zachry Department of Civil Engineering, Texas A\&M University, 3136 TAMU, College Station, TX 77843-3136
}

\begin{abstract}
Most of the vibration based damage detection methods are based on changes in frequencies, mode shapes, mode shape curvature, and flexibilities. These methods are limited and typically can only detect the presence and location of damage. Current methods seldom can identify the exact severity of damage to structures. This paper will present research in the development of a new non-destructive evaluation method to identify the existence, location, and severity of damage for structural systems. The method utilizes the concept of invariant stress resultants (ISR). The basic concept of ISR is that at any given cross section the resultant internal force distribution in a structural member is not affected by the inflicted damage. The method utilizes dynamic analysis of the structure to simulate direct measurements of acceleration, velocity and displacement simultaneously. The proposed dynamic ISR method is developed and utilized to detect the damage of corresponding changes in mass, damping and stiffness. The objectives of this research are to develop the basic theory of the dynamic ISR method, apply it to the specific types of structures, and verify the accuracy of the developed theory. Numerical results that demonstrate the application of the method will reflect the advanced sensitivity and accuracy in characterizing multiple damage locations.
\end{abstract}

\section{Introduction}

Damage is the main cause of structural failures. Thus, it is important to identify minor damages early on to avoid failure. Damage can appear as cracks, corrosion and spalling, as well as local deformation, both inside and outside structures. Yao (1972) defined damage as "the occurrence of any modification in a part, or parts of a structure that can impair the intended performance of the structure." Thus, damage identification must compare two different states of a structure: the initial, undamaged state, and the final state (Farrar and Worden, 2007). Therefore, the definition of damage provides a notion on how to obtain the change in system performance.

In a general case, compliance, mass, damping, and stiffness of the $i^{\text {th }}$ member of the system can be defined as $F_{i}, m_{i}, c_{i}$, and $k_{i}$, with changes defined as $\delta F_{i}$, $\delta m_{i}, \delta c_{i}$, and $\delta k_{i}$, respectively.

In many situations, just knowing the mechanical manifestation of damage is not sufficient. The goal of the presented research is to identify and predict damage so as to decrease loss. Structural health monitoring (SHM) involves the process of implementing a damage identification and an evaluation of the current status of the systems' health. Inevitably, long-term aging and damage accumulation will impact the intended performance of the structure, due to the operational environment. The SHM output process periodically renews response information, which shows the current state of the structure. Therefore, when subject to external excitation, such as earthquake or wind loads, SHM provides rapid condition screening to display information concerning system states and the operational evaluation of the system (Farrar and Worden, 2007).

Rytter (1993) gives the four principal levels of SHM:

- Level I: Only identify if damage has occurred

- Level II: Identify and locate damage

- Level III: Identify, locate and estimate damage severity

- Level IV: Identify, locate, estimate, and evaluate the impact of damage on the structure.

Non-destructive evaluation (NDE) describes a wide set of analysis approaches to perform SHM without causing damage to the physical structure. Thus, the aforementioned SHM levels also can be used to classify NDE. Most published methods can be classified as the first two levels, however researchers continue to work towards developing Level III \& IV methods. The generalized indicators used to characterize damage in a Level III NDE method are (Stubbs, 1992):

$$
\begin{gathered}
\text { Mass damage severity }=\frac{\delta m_{i}}{m_{i}} \\
\text { Damping damage severity }=\frac{\delta c_{i}}{c_{i}} \\
\text { Stiffness damage severity }=\frac{\delta k_{i}}{k_{i}}
\end{gathered}
$$

If the damage severity is zero for a localized region, there is no damage; otherwise, damage is present in that region. Dincal and Stubbs (2013) presented the Static

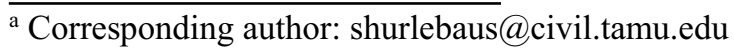


Invariant Stress Resultants (ISR) method, which could accurately locate and size damage in a Timoshenko beam. Li (2013) expanded this method by using structural member energy strains to get the stiffness damage severity. The method was applied to 1-D, 2-D, and 3-D systems with single or multiple damage locations. This method was effective in detecting stiffness damage of structures during static loadings situations. However the static ISR method did not consider any changes in mass and damping, which are important parameters to be considered in the case of dynamic loading.

The current work presents an effective method to detect the existence, location and severity of damage to predict the state of structures. The proposed method based on dynamic ISR is developed and successfully demonstrated to detect damage, and corresponding changes in mass and stiffness in models of various degree of freedom. The objectives of this research are to:

1) Develop the basic theory of the dynamic ISR method and apply it to multiple systems

2) Demonstrate the accuracy of the developed theory using exact structural response quantities simulated using the static analysis of finite element models.

The presented paper is outlined as follows: this introduction section provided a problem statement, background of relevant literature, technical needs, and objectives. Section 2 explains the basic dynamic ISR of a single degree of freedom system, while Section 3 expands the derivation to describe the dynamic ISR of a multi degree of freedom system. The second half of Section 3 demonstrates and presents application of the dynamic ISR for two and five degree of freedom systems. Finally, Section 4 provides conclusion and future work.

\section{Single degree of freedom system}

\subsection{Overview of the dynamic ISR method}

The basic concept of ISR is that the resultant internal force distribution (and stress resultants) in a structural member is not affect by inflicted damage at any given cross section. Instead, damage is expressed as changes in member stiffness and damping properties. Therefore, the ISR that is presented in local coordinates equals the external forces in global coordinates. A benefit seen from this approach is that it is more straightforward and easily implemented, lending itself to computational efficiencies. Additionally, values for the external force and system parameters (mass, stiffness, and damping) are not necessary during simulation.

The dynamic ISR methodology assumes that the initial and final systems are subjected to the same external loading. It also assumes that the connectivity between members remains constant in both pre-damage and post-damage cases. Furthermore, the proposed methodology is derived from the fundamental principles of mechanics for structures undergoing vibration. For a mass-spring-damping system, the equation of motion based on basic equilibrium and the damage severity is solved using a numerical method using acceleration, velocity, and displacement data obtained at a specific location. Based on the results obtained for an element, the existence, location, and severity of damage are detected.

\subsection{Application to SDOF system}

To assist in introducing the dynamic ISR method, a single degree of freedom (SDOF) mass-damping-spring system is first described. Figure 1 depicts two systems: pre- and post-damage. The mass, damping, and stiffness for the pre-damaged system are $m, c$, and $k$, and $m^{*}, c^{*}$, and $k^{*}$ for the post-damaged system. The stress resultants for the pre-damaged system and post-damage system are both $p(t)$ where $t=$ time. Based on the ISR assumption, the external dynamic forces for both cases are alike, $P(t)$.
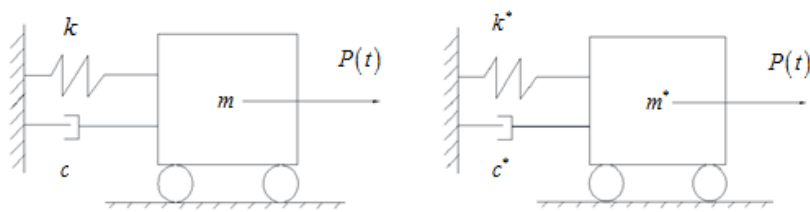

Figure 1. Pre- and post-damaged system SDOF.

Based on the parameters defined, the equation of motion for the undamaged system is

$$
m \ddot{x}+c \dot{x}+k x=P(t)
$$

and the equation of motion for the damaged system is

$$
m^{*} \ddot{x}^{*}+c^{*} \dot{x}^{*}+k^{*} x^{*}=P(t)
$$

It is assumed that the initial acceleration $\ddot{x}$, velocity $\dot{x}$, and displacement $x$, and the damaged acceleration $\ddot{x}^{*}$, velocity $\dot{x}^{*}$, and displacement $x^{*}$ are known at a specific time. Because $P$ is a function of time $t$, the acceleration, velocity and displacement for both cases are also a function of time $t$.

In this example, the potential damage may be expressed as a local decrease in mass, damping and stiffness in the structural member. As mentioned in the assumption, the external loading in both pre-damage and post-damage are the same. Based on this relationship, equations in global coordinates can be established to show the results of invariant stress resultants in local coordinates.

Equating Eq. (1) and Eq. (2) yields

$$
m \ddot{x}+c \dot{x}+k x=m^{*} \ddot{x}^{*}+c^{*} \dot{x}^{*}+k^{*} x^{*}
$$

Dividing by $k^{*}$ and assuming $t=t_{1}$, Eq. (3) can be rewritten as

$\left[\ddot{x}\left(t_{1}\right)-\ddot{x}^{*}\left(t_{1}\right) \dot{x}\left(t_{1}\right)-\dot{x}^{*}\left(t_{1}\right) x\left(t_{1}\right)\right]\left[\begin{array}{c}\frac{m}{k^{*}} \\ \frac{m^{*}}{k^{*}} \\ \frac{c}{k^{*}} \\ \frac{c^{*}}{k^{*}} \\ \frac{k}{k^{*}}\end{array}\right]=\left[x^{*}\left(t_{1}\right)\right](4)$ 
In solving Eq. (4), $\beta_{i}$ can be defined as $\beta_{1}=\frac{m}{k^{*}}$, $\beta_{2}=\frac{m^{*}}{k^{*}}, \quad \beta_{3}=\frac{c}{k^{*}}, \quad \beta_{4}=\frac{c^{*}}{k^{*}}, \quad \beta_{5}=\frac{k}{k^{*}}$. The damage index $\beta$ for mass, damping, and stiffness is

$$
\begin{gathered}
\beta_{m}=\frac{\beta_{1}}{\beta_{2}}=\frac{\left(\frac{m}{k^{*}}\right)}{\left(\frac{m^{*}}{k^{*}}\right)}=\frac{m}{m^{*}} \\
\beta_{c}=\frac{\beta_{3}}{\beta_{4}}=\frac{\left(\frac{c}{k^{*}}\right)}{\left(\frac{c^{*}}{k^{*}}\right)}=\frac{c}{c^{*}} \\
\beta_{k}=\beta_{5}=\frac{k}{k^{*}}
\end{gathered}
$$

Thus, the damage severity $\alpha$ for mass, damping and stiffness is

$$
\begin{aligned}
& \alpha_{m}=\frac{1}{\beta_{m}}-1 \\
& \alpha_{c}=\frac{1}{\beta_{c}}-1 \\
& \alpha_{k}=\frac{1}{\beta_{k}}-1
\end{aligned}
$$

Eq. (4) is solved for the damage indicators at different times $t$ using the linear least square method to minimize the calculated error.

\subsection{Simulation of SDOF system}

To successfully demonstrate the presented theory, a mass-damping-spring model was built using SAP2000. The pre-damaged model contains a particle and a link support, assigned a damping and stiffness value. By decreasing the values of the mass of the particle and the link coefficients, a post-damage model is developed. Then the same sinusoidal dynamic load, $P(t)$ was applied to the particle for both initial and final cases.

Table 1. Specified parameters for the SDOF damage cases.

\begin{tabular}{|c|c|c|c|c|}
\hline Case & $\begin{array}{c}\text { Mass } \\
\text { (kip-s } 2 / \text { in })\end{array}$ & $\begin{array}{c}\text { Damping } \\
\text { (kip-s/in) }\end{array}$ & $\begin{array}{c}\text { Stiffness } \\
\text { (kip/in) }\end{array}$ & $\begin{array}{c}\text { Force } \\
\text { Amplitude } \\
\text { (kips) }\end{array}$ \\
\hline Initial & 3.00 & 1.00 & 2.00 & 1.00 \\
\hline 1 & 2.40 & 1.00 & 2.00 & 1.00 \\
\hline 2 & 3.00 & 0.90 & 2.00 & 1.00 \\
\hline 3 & 3.00 & 1.00 & 1.40 & 1.00 \\
\hline 4 & 2.40 & 0.90 & 2.00 & 1.00 \\
\hline 5 & 2.40 & 1.00 & 1.40 & 1.00 \\
\hline 6 & 3.00 & 0.90 & 1.40 & 1.00 \\
\hline 7 & 2.40 & 0.90 & 1.40 & 1.00 \\
\hline
\end{tabular}

* Shaded region indicates noteworthy departure from initial value.

For the SDOF system, only one damage location can be specified, but multiple damage types can be combined in the simulation cases. Different damage combinations include reduction of the mass, damping, and stiffness. Table 1 summarizes the seven possible combinations designed for the simulation. The damage index and severity values corresponding to the each case specified are presented in Table 2.

Table 2. Theoretical damage index and severity values based on the specified parameters for the SDOF damage cases.

\begin{tabular}{|c|c|c|c|c|c|c|}
\hline \multirow{2}{*}{ Case } & \multicolumn{2}{|c|}{ Mass } & \multicolumn{2}{c|}{ Damping } & \multicolumn{2}{c|}{ Stiffness } \\
\cline { 2 - 7 } & $\beta_{m}$ & $\alpha_{m}$ & $\beta_{c}$ & $\alpha_{c}$ & $\beta_{k}$ & $\alpha_{k}$ \\
\hline 1 & 1.25 & -0.20 & 1.00 & 0.00 & 1.00 & 0.00 \\
\hline 2 & 1.00 & 0.00 & 1.11 & -0.10 & 1.00 & 0.00 \\
\hline 3 & 1.00 & 0.00 & 1.00 & 0.00 & 1.43 & -0.30 \\
\hline 4 & 1.25 & -0.20 & 1.11 & -0.10 & 1.00 & 0.00 \\
\hline 5 & 1.25 & -0.20 & 1.00 & 0.00 & 1.43 & -0.30 \\
\hline 6 & 1.00 & 0.00 & 1.11 & -0.10 & 1.43 & -0.30 \\
\hline 7 & 1.25 & -0.20 & 1.11 & -0.10 & 1.43 & -0.30 \\
\hline
\end{tabular}

\subsection{SDOF system results}

The damage index and damage severity values for each case can be calculated using the acceleration, velocity and displacement data from the pre- and post-damage systems calculated directly via dynamic analysis using SAP2000. The calculated damage indicies and damage severities are presented in Table 3 and Table 4, respectively. In Table 3, percent error is between the specified and calculated damage indices. Table 4 expresses the absolute error (difference) between the calculated damage severities and the theoretical values found in Table 2 based directly on the specified input parameters. The absolute difference was selected to prevent zero denominator that would result when there is no change in parameter.

Table 3. Damage index results for the SDOF cases as determined using dynamic ISR.

\begin{tabular}{|c|c|c|c|c|c|c|}
\hline \multirow{3}{*}{ Case } & \multicolumn{2}{|c|}{$\beta_{m}=m / m^{*}$} & \multicolumn{2}{c|}{$\beta_{c}=c / c^{*}$} & \multicolumn{2}{c|}{$\beta_{k}=k / k^{*}$} \\
\cline { 2 - 7 } & $\begin{array}{c}\text { Calc. } \\
\text { Value }\end{array}$ & $\begin{array}{c}\text { Error } \\
(\%)\end{array}$ & $\begin{array}{c}\text { Calc. } \\
\text { Value }\end{array}$ & $\begin{array}{c}\text { Error } \\
(\%)\end{array}$ & $\begin{array}{c}\text { Calc. } \\
\text { Value }\end{array}$ & $\begin{array}{c}\text { Error } \\
(\%)\end{array}$ \\
\hline 1 & 1.25 & 0.00 & 1.00 & 0.00 & 1.00 & 0.00 \\
\hline 2 & 1.00 & 0.00 & 1.11 & 0.00 & 1.00 & 0.00 \\
\hline 3 & 1.00 & 0.00 & 1.00 & 0.00 & 1.43 & 0.00 \\
\hline 4 & 1.25 & 0.00 & 1.11 & 0.01 & 1.00 & 0.00 \\
\hline 5 & 1.25 & 0.00 & 1.00 & 0.00 & 1.43 & 0.00 \\
\hline 6 & 1.00 & 0.00 & 1.11 & 0.01 & 1.43 & 0.00 \\
\hline 7 & 1.25 & 0.00 & 1.11 & 0.00 & 1.43 & 0.00 \\
\hline
\end{tabular}

Table 4. Damage severity results for the SDOF cases as determined using dynamic ISR.

\begin{tabular}{|c|c|c|c|c|c|c|}
\hline \multirow{3}{*}{ Case } & \multicolumn{2}{|c|}{$\alpha_{m}=1 / \beta_{m}-1$} & \multicolumn{2}{c|}{$\alpha_{c}=1 / \beta_{c}-1$} & \multicolumn{2}{c|}{$\alpha_{k}=1 / \beta_{k}-1$} \\
\cline { 2 - 7 } & $\begin{array}{c}\text { Calc. } \\
\text { Value }\end{array}$ & $\begin{array}{c}\text { Abs. } \\
\text { Error }\end{array}$ & $\begin{array}{c}\text { Calc. } \\
\text { Value }\end{array}$ & $\begin{array}{c}\text { Abs. } \\
\text { Error }\end{array}$ & $\begin{array}{c}\text { Calc. } \\
\text { Value }\end{array}$ & $\begin{array}{c}\text { Abs. } \\
\text { Error }\end{array}$ \\
\hline 1 & -0.20 & 0.00 & 0.00 & 0.00 & 0.00 & 0.00 \\
\hline 2 & 0.00 & 0.00 & -0.10 & 0.00 & 0.00 & 0.00 \\
\hline 3 & 0.00 & 0.00 & 0.00 & 0.00 & -0.30 & 0.00 \\
\hline 4 & -0.20 & 0.00 & -0.10 & 0.00 & 0.00 & 0.00 \\
\hline 5 & -0.20 & 0.00 & 0.00 & 0.00 & -0.30 & 0.00 \\
\hline 6 & 0.00 & 0.00 & -0.10 & 0.00 & -0.30 & 0.00 \\
\hline 7 & -0.20 & 0.00 & -0.10 & 0.00 & -0.30 & 0.00 \\
\hline
\end{tabular}

By definition, the damage indices presented in Table 3 reflect the ratio of the original, pre-damage and post-damage parameters. For example, $\beta_{m}=1.25$ represents the ratio of the initial mass to the final mass. The percent error in Table 3 indicates the difference between the initial and final damage indices over the 
initial. In all cases, the percent values are well smaller than standard criterion, $2 \%$. The results listed in Table 4 can directly indicate the current state of the structure. Also by definition, the value $\alpha_{m}=-0.20$ indicates a $20 \%$ mass reduction. The absolute error in Table 4 expresses the absolute difference between the calculated damage severities and the actual one and the values are less than the standard criterion 0.02 .

\subsection{Conclusions for SDOF system}

By comparing the results from different cases, the following conclusions can be drawn effectively,

- The application of the dynamic ISR method for a SDOF indicates the superiority of a Level III method. Although the SDOF model repeatedly simulated one damage location, it still provided very effective results to identify the type and the severity of the damage. The damage index errors are quite small; all results are less than the standard $2 \%$ detection error.

- The dynamic ISR method can quantify damage severity in mass, stiffness, and damping when system parameters are unknown.

- Damage detection via the dynamic ISR method in a SDOF system is not limited to structures with a single damage case; it can simultaneously characterize various changes in mass, damping and stiffness.

- Calculation accuracy can be improved by increasing the number of the sample cases and output step size of the data.

- Accuracy of the results largely depends on the data. This problem can be easily solved in simulated results by increasing the number of significant digits, but in practice, high precision sensors may be necessary.

\section{Multi Degree of Freedom Systems}

\subsection{Overview of the dynamic ISR method}

\subsubsection{Introduction}

As presented in Section 2, the dynamic ISR method is efficient for a SDOF system. However, this theory is not limited by the system type. Therefore, the dynamic ISR must be suitable for multi degree of freedom (MDOF) systems. Compared with a SDOF system, a MDOF system can provide the potential for more damage locations, which helps to effectively test whether the proposed method meets the requirements of a Level III method. Additionally, a general approach for MDOF will be presented, which will help to simplify the theory and allow it to be widely used for different cases.

\subsubsection{General Approach}

For a MDOF system, the model can be taken as a multi degree of freedom mass-damping-spring system as shown in Figure 2.

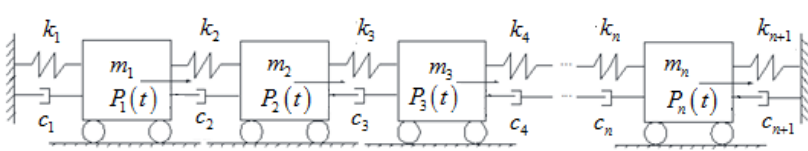

Figure 2. Mass-damping-stiffness of MDOF system

To obtain a general solution for the MDOF system, the focus is on the $i^{\text {th }}$ member shown in Figure 3. For the $i^{\text {th }}$ member, the mass for initial and final system are $m_{i}$ and $m_{i}{ }^{*}$, respectively. The damping and stiffness, on the left side of the respective mass, for pre-damaged system is $c_{i}$, and $k_{i}$ and for the post-damaged system is $c_{i}{ }^{*}$ and $k_{i}^{*}$. For the right side of the mass, the damping and stiffness for pre-damaged system is $c_{i+1}$ and $k_{i+1}$ and for the post-damaged system is $c_{i+1}{ }^{*}$ and $k_{i+1}{ }^{*}$. The stress resultants for the pre-damage system and post-damage system both are $p_{i}(t)$. Based on the assumption of ISR, the external dynamic forces for both cases are the same, $P_{i}(\mathrm{t})=\hat{P}_{i} \cos \omega \mathrm{t}$, where $\hat{P}$ is the amplitude of the dynamic force. The values of the above parameters are unknown.
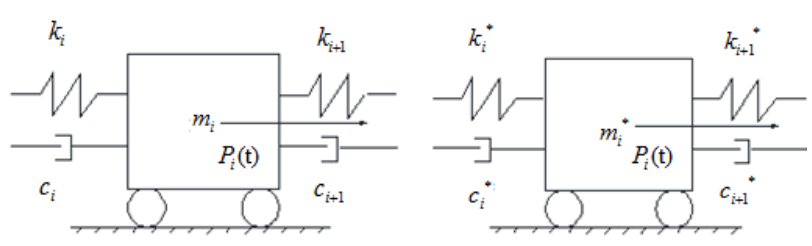

Figure 3. The $i^{t h}$ member for pre- and post-damage cases.

The equation of motion for the undamaged system may be expressed as

$$
\begin{aligned}
m_{i} \ddot{x}_{i} & +c_{i}\left(\dot{x}_{i}-\dot{x}_{i-1}\right)+c_{i+1}\left(\dot{x}_{i+1}-\dot{x}_{i}\right) \\
& +k_{i}\left(x_{i}-x_{i-1}\right)+k_{i+1}\left(x_{i+1}-x_{i}\right)=P(t)
\end{aligned}
$$

Similarly, for the damaged system,

$$
\begin{aligned}
m_{i}^{*} \ddot{x}_{i}^{*} & +c_{i}^{*}\left(\dot{x}_{i}^{*}-\dot{x}_{i-1}{ }^{*}\right)+c_{i+1}{ }^{*}\left(\dot{x}_{i+1}{ }^{*}-\dot{x}_{i}^{*}\right) \\
& +k_{i}^{*}\left(x_{i}^{*}-x_{i-1}^{*}\right)+k_{i+1}{ }^{*}\left(x_{i+1}{ }^{*}-x_{i}^{*}\right)=P(t)
\end{aligned}
$$

It is assumed that the initial acceleration $\ddot{x}$, velocity $\dot{x}$, displacement $x$ and damaged acceleration $\ddot{x}^{*}$, velocity $\dot{x}^{*}$, displacement $x^{*}$ are known at a specific time.

In the $i^{\text {th }}$ member, the damage is expressed as a local decrease in mass, damping and stiffness in the structural member. At the cross-section, the consequence of the stress resultants is shown as the external force in global coordinates (Figure 4). As mentioned in the assumption, the external loading in both pre-damage and post-damage are the same. Based on this relationship, equations in global coordinates can be established to show the results of ISR in the local coordinates.
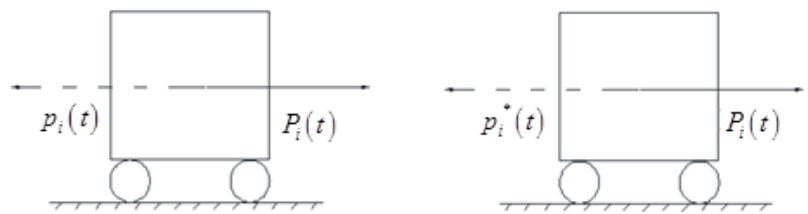

Figure 4. Stress resultants and external force in initial and final systems. 
Equating Eq. (11) and Eq. (12) yields

$$
\begin{aligned}
& m_{i} \ddot{x}_{i}+c_{i}\left(\dot{x}_{i}-\dot{x}_{i-1}\right)+c_{i+1}\left(\dot{x}_{i+1}-\dot{x}_{i}\right)+k_{i}\left(x_{i}-x_{i-1}\right) \\
& +k_{i+1}\left(x_{i+1}-x_{i}\right)=m_{i} \ddot{x}_{i}^{*}+c_{i}^{*}\left(\dot{x}_{i}^{*}-\dot{x}_{i-1}{ }^{*}\right) \\
& +c_{i+1}{ }^{*}\left(\dot{x}_{i+1}{ }^{*}-\dot{x}_{i}^{*}\right)+k_{i}^{*}\left(x_{i}^{*}-x_{i-1}{ }^{*}\right)+k_{i+1}{ }^{*}\left(x_{i+1}{ }^{*}-x_{i}^{*}\right)
\end{aligned}
$$

Dividing by $k_{i+1}{ }^{*}$ and assuming $t=t_{1}$, Eq. (13) is rewritten

$$
\begin{aligned}
& \beta_{1} \ddot{x}_{i}(t)-\beta_{2} \ddot{x}_{i}^{*}(t)+\beta_{3}\left(\dot{x}_{i}(t)-\dot{x}_{i-1}(t)\right) \\
& -\beta_{4}\left(\dot{x}_{i}^{*}(t)-\dot{x}_{i-1}^{*}(t)\right)+\beta_{5}\left(\dot{x}_{i+1}(t)-\dot{x}_{i}(t)\right) \\
& -\beta_{6}\left(\dot{x}_{i+1}{ }^{*}(t)-\dot{x}_{i}^{*}(t)\right)+\beta_{7}\left(x_{i}(t)-x_{i-1}(t)\right) \\
& -\beta_{8}\left(x_{i}^{*}(t)-x_{i-1}^{*}(t)\right)+\beta_{9}\left(x_{i+1}(t)-x_{i}(t)\right) \\
& =\left(x_{i+1}{ }^{*}(t)-x_{i}^{*}(t)\right)
\end{aligned}
$$

where $\quad \beta_{1}=\frac{m_{i}}{k_{i+1}{ }^{*}}, \quad \beta_{2}=\frac{m_{i}{ }^{*}}{k_{i+1}{ }^{*}}, \quad \beta_{3}=\frac{c_{i}}{{k_{i+1}}^{*}}, \quad \beta_{4}=\frac{c_{i}{ }^{*}}{k_{i+1}{ }^{*}}$, $\beta_{5}=\frac{c_{i+1}}{k_{i+1}{ }^{*}}, \quad \beta_{6}=\frac{c_{i+1}{ }^{*}}{k_{i+1}{ }^{*}}, \quad \beta_{7}=\frac{k_{i}{ }^{*}}{k_{i+1}{ }^{*}}, \quad \beta_{8}=\frac{k_{i}^{*}}{k_{i+1}{ }^{*}}, \quad$ and $\beta_{9}=\frac{k_{i+1}}{k_{i+1}{ }^{*}}$.

As a result, the damage indices may be expressed as

$$
\begin{gathered}
\beta_{m_{i}}=\frac{m_{i}}{m_{i}^{*}}=\frac{\beta_{1}}{\beta_{2}} \\
\beta_{c_{i}}=\frac{c_{i}}{c_{i}^{*}}=\frac{\beta_{3}}{\beta_{4}} \\
\beta_{c_{i+1}}=\frac{c_{i+1}}{c_{i+1}^{*}}=\frac{\beta_{5}}{\beta_{6}} \\
\beta_{k_{1}}=\frac{k_{i}}{k_{i}^{*}}=\frac{\beta_{7}}{\beta_{8}} \\
\beta_{k_{i+1}}=\frac{k_{i+1}}{k_{i+1}{ }^{*}}=\beta_{9}
\end{gathered}
$$

Thus, the damage severities are expressed as

$$
\begin{aligned}
\alpha_{m_{i}} & =\frac{1}{\beta_{m_{i}}}-1 \\
\alpha_{c_{i}} & =\frac{1}{\beta_{c_{i}}}-1 \\
\alpha_{c_{i+1}} & =\frac{1}{\beta_{c_{i+1}}}-1 \\
\alpha_{k} & =\frac{1}{\beta_{k}}-1 \\
\alpha_{k_{i+1}} & =\frac{1}{\beta_{k_{I+1}}}-1
\end{aligned}
$$

Again, the linear least square method is used to determine the damage index values.

\subsection{Simulation of a 2-DOF system}

To demonstrate the application of the dynamic ISR methods' general approach for MDOF, a pair of two degree of freedom (2-DOF) models were built in
SAP2000 for the pre- and post-damage conditions (Figure 5 and Figure 6, respectively).

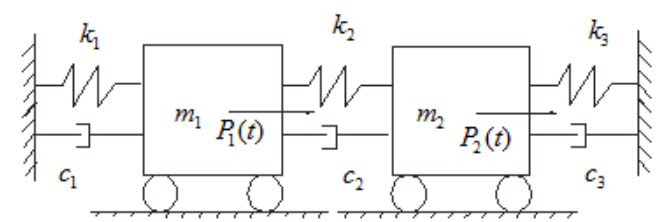

Figure 5. Two degree of freedom system model for undamaged case.

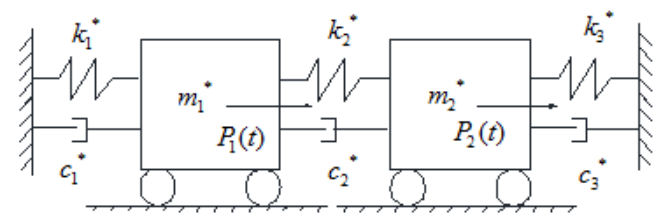

Figure 6. Two degree of freedom system model for damaged case.

As depicted in Figure 5, the pre-damage model contains two particles and three link supports, which can be assigned damping and stiffness parameters. The similarly configured post-damage model in Figure 6 was developed by decreasing the values of the particles mass and link coefficients. The dynamic load $P_{1}(t)$ was applied to the first particle and $P_{2}(t)$ to the second particle for both initial and final systems.

For the 2-DOF system, multiple types of damage are

\begin{tabular}{|c|c|c|c|c|c|c|c|c|}
\hline \multirow[b]{2}{*}{ Case } & \multicolumn{2}{|c|}{$\begin{array}{c}\text { Mass } \\
\left(\text { kip-s } \text { s }^{2}\right) / \text { in }\end{array}$} & \multicolumn{3}{|c|}{$\begin{array}{l}\text { Damping } \\
\text { (kip-s/in) }\end{array}$} & \multicolumn{3}{|c|}{$\begin{array}{c}\text { Stiffness } \\
\text { (kip/in) }\end{array}$} \\
\hline & 1 & 2 & 1 & 2 & 3 & 1 & 2 & 3 \\
\hline Initial & 3.00 & 2.00 & 1.50 & 1.40 & 1.30 & 1.00 & 1.10 & 1.20 \\
\hline 1 & 2.70 & 2.00 & 1.50 & 1.40 & 1.30 & 1.00 & 1.10 & 1.20 \\
\hline 2 & 3.00 & 1.78 & 1.50 & 1.40 & 1.30 & 1.00 & 1.10 & 1.20 \\
\hline 3 & 3.00 & 2.00 & 1.43 & 1.40 & 1.30 & 1.00 & 1.10 & 1.20 \\
\hline 4 & 3.00 & 2.00 & 1.50 & 1.32 & 1.30 & 1.00 & 1.10 & 1.20 \\
\hline 5 & 3.00 & 2.00 & 1.50 & 1.40 & 1.21 & 1.00 & 1.10 & 1.20 \\
\hline 6 & 3.00 & 2.00 & 1.50 & 1.40 & 1.30 & 0.88 & 1.10 & 1.20 \\
\hline 7 & 3.00 & 2.00 & 1.50 & 1.40 & 1.30 & 1.00 & 0.96 & 1.20 \\
\hline 8 & 3.00 & 2.00 & 1.50 & 1.40 & 1.30 & 1.00 & 1.10 & 1.03 \\
\hline 9 & 2.70 & 1.78 & 1.43 & 1.32 & 1.21 & 1.00 & 1.10 & 1.20 \\
\hline 10 & 2.70 & 1.78 & 1.50 & 1.40 & 1.30 & 0.88 & 0.96 & 1.03 \\
\hline 11 & 3.00 & 2.00 & 1.43 & 1.32 & 1.21 & 0.88 & 0.96 & 1.03 \\
\hline 12 & 2.70 & 1.78 & 1.43 & 1.32 & 1.21 & 0.88 & 0.96 & 1.03 \\
\hline
\end{tabular}
applied at several locations. These different damages types include reduction of mass, damping, and stiffness. Twelve combinations were designed and are summarized in Table 5, and the corresponding theoretical damage index and severity values for the 2-DOF damage cases are presented in Table 6 and Table 7.

As mentioned in the general approach of MDOF, the simulation procedure focuses primarily on the structural members. Therefore, results related to the $i^{\text {th }}$ member describe changes to the parameters related to itself.

The amplitude of the applied forces $P_{1}$ and $P_{2}$ were 10 kips and 8 kips, respectively. The acceleration, velocity and displacement for initial and final systems can be calculated directly by dynamic analysis using SAP2000. Using the output from the finite element program, the damage indices and damage severity are calculated.

Table 5. Specified parameters for the 2-DOF damage cases. 
Table 6. Theoretical damage index values based on the specified parameters for the 2-DOF cases.

\begin{tabular}{|c|c|c|c|c|c|c|c|c|}
\hline Case & $\beta_{m_{1}}$ & $\beta_{m_{2}}$ & $\beta_{c_{1}}$ & $\beta_{c_{2}}$ & $\beta_{c_{3}}$ & $\beta_{k_{1}}$ & $\beta_{k_{2}}$ & $\beta_{k_{3}}$ \\
\hline 1 & 1.11 & 1.00 & 1.00 & 1.00 & 1.00 & 1.00 & 1.00 & 1.00 \\
\hline 2 & 1.00 & 1.12 & 1.00 & 1.00 & 1.00 & 1.00 & 1.00 & 1.00 \\
\hline 3 & 1.00 & 1.00 & 1.05 & 1.00 & 1.00 & 1.00 & 1.00 & 1.00 \\
\hline 4 & 1.00 & 1.00 & 1.00 & 1.06 & 1.00 & 1.00 & 1.00 & 1.00 \\
\hline 5 & 1.00 & 1.00 & 1.00 & 1.00 & 1.08 & 1.00 & 1.00 & 1.00 \\
\hline 6 & 1.00 & 1.00 & 1.00 & 1.00 & 1.00 & 1.14 & 1.00 & 1.00 \\
\hline 7 & 1.00 & 1.00 & 1.00 & 1.00 & 1.00 & 1.00 & 1.15 & 1.00 \\
\hline 8 & 1.00 & 1.00 & 1.00 & 1.00 & 1.00 & 1.00 & 1.00 & 1.16 \\
\hline 9 & 1.11 & 1.12 & 1.05 & 1.06 & 1.08 & 1.00 & 1.00 & 1.00 \\
\hline 10 & 1.11 & 1.12 & 1.00 & 1.00 & 1.00 & 1.14 & 1.15 & 1.16 \\
\hline 11 & 1.00 & 1.00 & 1.05 & 1.06 & 1.08 & 1.14 & 1.15 & 1.16 \\
\hline 12 & 1.11 & 1.12 & 1.05 & 1.06 & 1.08 & 1.14 & 1.15 & 1.16 \\
\hline
\end{tabular}

Table 7. Theoretical damage severity values based on the specified parameters for the 2-DOF cases.

\begin{tabular}{|c|c|c|c|c|c|c|c|c|}
\hline Case & $\alpha_{m_{1}}$ & $\alpha_{m_{2}}$ & $\alpha_{c_{1}}$ & $\alpha_{c_{2}}$ & $\alpha_{c_{3}}$ & $\alpha_{k_{1}}$ & $\alpha_{k_{2}}$ & $\alpha_{k_{3}}$ \\
\hline 1 & -0.10 & 0.00 & 0.00 & 0.00 & 0.00 & 0.00 & 0.00 & 0.00 \\
\hline 2 & 0.00 & -0.11 & 0.00 & 0.00 & 0.00 & 0.00 & 0.00 & 0.00 \\
\hline 3 & 0.00 & 0.00 & -0.05 & 0.00 & 0.00 & 0.00 & 0.00 & 0.00 \\
\hline 4 & 0.00 & 0.00 & 0.00 & -0.06 & 0.00 & 0.00 & 0.00 & 0.00 \\
\hline 5 & 0.00 & 0.00 & 0.00 & 0.00 & -0.07 & 0.00 & 0.00 & 0.00 \\
\hline 6 & 0.00 & 0.00 & 0.00 & 0.00 & 0.00 & -0.12 & 0.00 & 0.00 \\
\hline 7 & 0.00 & 0.00 & 0.00 & 0.00 & 0.00 & 0.00 & -0.13 & 0.00 \\
\hline 8 & 0.00 & 0.00 & 0.00 & 0.00 & 0.00 & 0.00 & 0.00 & -0.14 \\
\hline 9 & -0.10 & -0.11 & -0.05 & -0.06 & -0.07 & 0.00 & 0.00 & 0.00 \\
\hline 10 & -0.10 & -0.11 & 0.00 & 0.00 & 0.00 & -0.12 & -0.13 & -0.14 \\
\hline 11 & 0.00 & 0.00 & -0.05 & -0.06 & -0.07 & -0.12 & -0.13 & -0.14 \\
\hline 12 & -0.10 & -0.11 & -0.05 & -0.06 & -0.07 & -0.12 & -0.13 & -0.14 \\
\hline
\end{tabular}

\subsection{2-DOF system results}

Following finite element simulation, the modeled output data is used to calculate the damage indices and damage severities. Table 8 , Table 9 , and Table 10 provide the calculated damage indices for mass, damping and stiffness, respectively. Table 11, Table 12, and Table 13 provide the calculated damage severities for mass, damping and stiffness, respectively.

Table 8. Mass damage index results for the 2-DOF cases as determined using dynamic ISR.

\begin{tabular}{|c|c|c|c|c|}
\hline \multirow{2}{*}{ Case } & \multicolumn{2}{|c|}{$\beta_{m_{1}}=m_{1} / m_{1}{ }^{*}$} & \multicolumn{2}{c|}{$\beta_{m_{2}}=m_{2} / m_{2}{ }^{*}$} \\
\cline { 2 - 5 } & Calc. Value & Error (\%) & Calc. Value & Error (\%) \\
\hline 1 & 1.11 & 0.00 & 1.00 & 0.00 \\
\hline 2 & 1.00 & 0.00 & 1.12 & 0.00 \\
\hline 3 & 1.00 & 0.00 & 1.00 & 0.02 \\
\hline 4 & 1.00 & 0.20 & 1.00 & 0.08 \\
\hline 5 & 1.00 & 0.02 & 1.00 & 0.00 \\
\hline 6 & 1.00 & 0.00 & 1.00 & 0.01 \\
\hline 7 & 1.00 & 0.04 & 1.00 & 0.02 \\
\hline 7 & 1.00 & 0.00 & 1.00 & 0.00 \\
\hline 8 & 1.11 & 0.00 & 1.12 & 0.00 \\
\hline 10 & 1.11 & 0.00 & 1.12 & 0.00 \\
\hline 11 & 1.00 & 0.00 & 1.00 & 0.00 \\
\hline 12 & 1.11 & 0.00 & 1.12 & 0.00 \\
\hline
\end{tabular}

The dynamic ISR method successfully detects the value of damage indices in 2-DOF system. When assessing the damage index results corresponding to the twelve cases in Table 8, Table 9, and Table 10, most percent errors are less than the standard percent error of $2 \%$. Compared to damage indices, the values of damage severity more effectively indicate the state of the structure. Using the data in Table 11, Table 12, and Table 13, it is easy to obtain the reduction of the parameter(s) in each case. Most of the calculated absolute error values are less than 0.02, demonstrating the effectiveness of the proposed method.

Table 9. Damping damage index results for the 2-DOF cases as determined using dynamic ISR.

\begin{tabular}{|c|c|c|c|c|c|c|}
\hline \multirow{3}{*}{ Case } & \multicolumn{2}{|c|}{$\beta_{c_{1}}=c_{1} / c_{1}{ }^{*}$} & \multicolumn{2}{c|}{$\beta_{c_{2}}=c_{2} / c_{2}{ }^{*}$} & \multicolumn{2}{c|}{$\beta_{c_{3}}=c_{3} / c_{3}{ }^{*}$} \\
\cline { 2 - 7 } & $\begin{array}{c}\text { Calc. } \\
\text { Value }\end{array}$ & $\begin{array}{c}\text { Error } \\
(\%)\end{array}$ & $\begin{array}{c}\text { Calc. } \\
\text { Value }\end{array}$ & $\begin{array}{c}\text { Error } \\
(\%)\end{array}$ & $\begin{array}{c}\text { Calc. } \\
\text { Value }\end{array}$ & $\begin{array}{c}\text { Error } \\
(\%)\end{array}$ \\
\hline 1 & 1.00 & 0.05 & 1.00 & 0.05 & 1.00 & 0.05 \\
\hline 2 & 1.00 & 0.02 & 1.00 & -0.29 & 1.00 & 0.00 \\
\hline 3 & 1.05 & -0.15 & 1.00 & -0.03 & 1.00 & -0.20 \\
\hline 4 & 1.00 & -0.16 & 1.07 & -0.21 & 1.00 & 0.06 \\
\hline 5 & 1.01 & 0.90 & 1.04 & 4.07 & 1.07 & 0.11 \\
\hline 6 & 1.00 & 0.37 & 0.99 & -1.43 & 1.00 & 0.11 \\
\hline 7 & 1.00 & 0.46 & 1.01 & 1.23 & 1.00 & 0.07 \\
\hline 8 & 1.00 & 0.05 & 1.00 & 0.05 & 1.00 & 0.00 \\
\hline 9 & 1.05 & 0.01 & 1.06 & -0.30 & 1.08 & 0.07 \\
\hline 10 & 1.00 & 0.01 & 1.00 & -0.14 & 1.00 & 0.05 \\
\hline 11 & 1.05 & 0.00 & 1.06 & -0.61 & 1.08 & 0.19 \\
\hline 12 & 1.05 & 0.03 & 1.06 & -0.13 & 1.08 & 0.00 \\
\hline
\end{tabular}

Table 10. Stiffness damage index results for the 2-DOF cases as determined using dynamic ISR.

\begin{tabular}{|c|c|c|c|c|c|c|}
\hline \multirow{2}{*}{ Case } & \multicolumn{2}{|c|}{$\beta_{k_{1}}=k_{1} / k_{1}^{*}$} & \multicolumn{2}{c|}{$\beta_{k_{2}}=k_{2} / k_{2}^{*}$} & \multicolumn{2}{c|}{$\beta_{k_{3}}=k_{3} / k_{3}^{*}$} \\
\cline { 2 - 7 } & $\begin{array}{c}\text { Calc. } \\
\text { Value }\end{array}$ & $\begin{array}{c}\text { Error } \\
(\%)\end{array}$ & $\begin{array}{c}\text { Calc. } \\
\text { Value }\end{array}$ & $\begin{array}{c}\text { Error } \\
(\%)\end{array}$ & $\begin{array}{c}\text { Calc. } \\
\text { Value }\end{array}$ & $\begin{array}{c}\text { Error } \\
(\%)\end{array}$ \\
\hline 1 & 1.00 & 0.66 & 1.00 & 0.00 & 1.00 & 0.57 \\
\hline 2 & 1.00 & 0.00 & 1.00 & -0.32 & 1.00 & -0.03 \\
\hline 3 & 1.00 & 0.29 & 1.00 & -0.18 & 1.00 & 0.00 \\
\hline 4 & 1.00 & 0.59 & 0.94 & -5.72 & 1.00 & -0.08 \\
\hline 5 & 0.99 & 1.00 & 1.07 & 6.84 & 1.00 & 0.39 \\
\hline 6 & 1.13 & 0.84 & 0.97 & -0.32 & 1.00 & 0.01 \\
\hline 7 & 0.99 & 0.59 & 1.17 & 2.13 & 1.00 & 0.18 \\
\hline 8 & 0.99 & 0.66 & 1.00 & 0.83 & 1.16 & 0.00 \\
\hline 9 & 1.00 & 0.01 & 1.00 & -0.30 & 1.00 & 0.09 \\
\hline 10 & 1.14 & 0.04 & 1.15 & -0.22 & 1.16 & 0.09 \\
\hline 11 & 1.14 & 0.00 & 1.15 & -0.63 & 1.16 & 0.15 \\
\hline 12 & 1.14 & 0.07 & 1.15 & -0.24 & 1.16 & 0.00 \\
\hline
\end{tabular}

Upon inspection of the calculated damage indices, potential damage is identified and its location(s) determined. The calculated damage severity may be consulted to easily obtain the level of reduction in each system parameter. The proposed framework thus demonstrates its effectiveness as a Level III method.

Table 11. Mass damage severity results for the 2-DOF cases as determined using dynamic ISR.

\begin{tabular}{|c|c|c|c|c|}
\hline \multirow{2}{*}{ Case } & \multicolumn{2}{|c|}{$\alpha_{m_{1}}=1 / \beta_{m_{1}}-1$} & \multicolumn{2}{c|}{$\alpha_{m_{2}}=1 / \beta_{m_{2}}-1$} \\
\cline { 2 - 5 } & Calc. Value & Abs. Error & Calc. Value & Abs. Error \\
\hline 1 & -0.10 & $-1.22 \mathrm{E}-05$ & 0.00 & $4.49 \mathrm{E}-05$ \\
\hline 2 & 0.00 & $-3.00 \mathrm{E}-06$ & -0.11 & $-5.14 \mathrm{E}-06$ \\
\hline 3 & 0.00 & $2.00 \mathrm{E}-05$ & 0.00 & $1.84 \mathrm{E}-04$ \\
\hline 4 & 0.00 & $-1.90 \mathrm{E}-03$ & 0.00 & $-7.82 \mathrm{E}-04$ \\
\hline 5 & 0.00 & $1.53 \mathrm{E}-04$ & 0.00 & $3.3 \mathrm{E}-05$ \\
\hline 6 & 0.00 & $3.10 \mathrm{E}-05$ & 0.00 & $5.30 \mathrm{E}-05$ \\
\hline 7 & 0.00 & $3.89 \mathrm{E}-04$ & 0.00 & $2.37 \mathrm{E}-04$ \\
\hline 8 & -0.00 & $4.32 \mathrm{E}-03$ & 0.00 & $4.5 \mathrm{E}-05$ \\
\hline 9 & -0.10 & $4.05 \mathrm{E}-06$ & -0.11 & $5.54 \mathrm{E}-06$ \\
\hline 10 & -0.10 & $4.05 \mathrm{E}-06$ & -0.11 & $1.58 \mathrm{E}-06$ \\
\hline 11 & 0.00 & $3.05 \mathrm{E}-04$ & 0.00 & $4.00 \mathrm{E}-06$ \\
\hline 12 & -0.10 & $4.05 \mathrm{E}-06$ & -0.11 & $1.58 \mathrm{E}-06$ \\
\hline
\end{tabular}


Table 12. Damping damage severity results for the 2-DOF cases as determined using dynamic ISR.

\begin{tabular}{|c|c|c|c|c|c|c|}
\hline \multirow{2}{*}{ Case } & \multicolumn{2}{|c|}{$\alpha_{c_{1}}=1 / \beta_{c_{1}}-1$} & \multicolumn{2}{c|}{$\alpha_{c_{2}}=1 / \beta_{c_{2}}-1$} & \multicolumn{2}{c|}{$\alpha_{c_{3}}=1 / \beta_{c_{3}}-1$} \\
\cline { 2 - 8 } & $\begin{array}{c}\text { Calc. } \\
\text { Value }\end{array}$ & Abs. Error & $\begin{array}{c}\text { Calc. } \\
\text { Value }\end{array}$ & Abs. Error & $\begin{array}{c}\text { Calc. } \\
\text { Value }\end{array}$ & Abs. Error \\
\hline 1 & 0.00 & $5.3 \mathrm{E}-04$ & 0.00 & $-4.53 \mathrm{E}-04$ & 0.00 & $-5.10 \mathrm{E}-04$ \\
\hline 2 & 0.00 & $2.35 \mathrm{E}-04$ & 0.00 & $-2.09 \mathrm{E}-03$ & 1.00 & $1.76 \mathrm{E}-04$ \\
\hline 3 & -0.05 & $-1.43 \mathrm{E}-03$ & 0.00 & $-5.00-03$ & 1.05 & $-1.95 \mathrm{E}-03$ \\
\hline 4 & 0.00 & $-1.63 \mathrm{E}-03$ & -0.06 & $2.01 \mathrm{E}-03$ & 0.00 & $5.66 \mathrm{E}-04$ \\
\hline 5 & 0.00 & $8.91 \mathrm{E}-03$ & -0.04 & $3.91 \mathrm{E}-02$ & -0.07 & $1.06 \mathrm{E}-03$ \\
\hline 6 & 0.00 & $3.76 \mathrm{E}-03$ & 0.01 & $1.46 \mathrm{E}-02$ & 0.00 & $1.08 \mathrm{E}-03$ \\
\hline 7 & 0.00 & $4.57 \mathrm{E}-03$ & 0.00 & $1.23 \mathrm{E} 00$ & 0.00 & $6.52 \mathrm{E}-04$ \\
\hline 8 & 0.00 & $5.34 \mathrm{E}-04$ & 0.00 & $4.53 \mathrm{E}-04$ & 0.00 & $5.13 \mathrm{E}-04$ \\
\hline 9 & -0.05 & $4.96 \mathrm{E}-04$ & -0.06 & $2.86 \mathrm{E}-03$ & -0.07 & $6.53 \mathrm{E}-04$ \\
\hline 10 & 0.00 & $1.43 \mathrm{E}-03$ & 0.00 & $1.35 \mathrm{E}-03$ & 0.00 & $5.23 \mathrm{E}-04$ \\
\hline 11 & -0.05 & $4.51 \mathrm{E}-06$ & -0.05 & $5.76 \mathrm{E}-03$ & -0.07 & $1.77 \mathrm{E}-03$ \\
\hline 12 & -0.05 & $2.82 \mathrm{E}-05$ & -0.05 & $1.12 \mathrm{E}-03$ & -0.07 & $2.25 \mathrm{E}-05$ \\
\hline
\end{tabular}

Table 13. Stiffness damage severity results for the 2-DOF cases as determined using dynamic ISR.

\begin{tabular}{|c|c|c|c|c|c|c|}
\hline \multirow{3}{*}{ Case } & \multicolumn{2}{|c|}{$\alpha_{k_{1}}=1 / \beta_{k_{1}}-1$} & \multicolumn{2}{c|}{$\alpha_{k_{2}}=1 / \beta_{k_{2}}-1$} & \multicolumn{2}{c|}{$\alpha_{k_{3}}=1 / \beta_{k_{3}}-1$} \\
\cline { 2 - 8 } & $\begin{array}{c}\text { Calc. } \\
\text { Value }\end{array}$ & $\begin{array}{c}\text { Abs. } \\
\text { Error }\end{array}$ & $\begin{array}{c}\text { Calc. } \\
\text { Value }\end{array}$ & $\begin{array}{c}\text { Abs. } \\
\text { Error }\end{array}$ & $\begin{array}{c}\text { Calc. } \\
\text { Value }\end{array}$ & $\begin{array}{c}\text { Abs. } \\
\text { Error }\end{array}$ \\
\hline 1 & 0.00 & $-6.67 \mathrm{E}-03$ & 0.00 & $5.93 \mathrm{E}-06$ & 0.00 & $-8.16 \mathrm{E}-03$ \\
\hline 2 & 0.00 & $6.26 \mathrm{E}-04$ & 0.00 & $-0.32 \mathrm{E}-03$ & 0.00 & $-3.23 \mathrm{E}-06$ \\
\hline 3 & 0.00 & $-2.94 \mathrm{E}-03$ & 0.00 & $-1.80 \mathrm{E}-03$ & 0.00 & $-2.66 \mathrm{E}-03$ \\
\hline 4 & 0.00 & $5.87 \mathrm{E}-03$ & 0.06 & $-1.00 \mathrm{E}-02$ & 0.00 & $-7.93 \mathrm{E}-04$ \\
\hline 5 & 0.01 & $1.01 \mathrm{E}-02$ & -0.06 & $6.40 \mathrm{E}-02$ & 0.00 & $3.87 \mathrm{E}-03$ \\
\hline 6 & -0.11 & $7.46 \mathrm{E}-03$ & 0.03 & $3.33 \mathrm{E}-02$ & 0.00 & $1.34 \mathrm{E}-04$ \\
\hline 7 & 0.00 & $5.92 \mathrm{E}-03$ & -0.15 & $1.59 \mathrm{E}-02$ & 0.00 & $1.77 \mathrm{E}-03$ \\
\hline 8 & 0.00 & $6.69 \mathrm{E}-03$ & 0.00 & $8.16 \mathrm{E}-03$ & -0.14 & $2.33 \mathrm{E}-03$ \\
\hline 9 & 0.00 & $7.00 \mathrm{E}-05$ & 0.00 & $3.04 \mathrm{E}-03$ & 0.00 & $8.76 \mathrm{E}-04$ \\
\hline 10 & -0.12 & $3.10 \mathrm{E}-04$ & -0.13 & $1.69 \mathrm{E}-03$ & -0.14 & $7.36 \mathrm{E}-03$ \\
\hline 11 & -0.12 & $8.51 \mathrm{E}-06$ & -0.13 & $4.80 \mathrm{E}-03$ & -0.14 & $1.32 \mathrm{E}-03$ \\
\hline 12 & -0.12 & $6.05 \mathrm{E}-04$ & -0.13 & $1.85 \mathrm{E}-03$ & -0.14 & $1.48 \mathrm{E}-05$ \\
\hline
\end{tabular}

As seen, the damage severity errors for mass detection are lesser than those related to changes in damping and stiffness. This can be attributed to characteristics of the general approach, where a member is represented by a particle and two links, and these links are shared with other members. Therefore, each shared link will have two groups of results from simulation. Averaging will improve the accuracy of the results at the link supports.

\subsection{Simulation procedure for a 5-DOF system}

Although the dynamic ISR method can effectively identify, locate and assess the severity of damage(s), in a 2-DOF system, this finding does not necessarily translate for all MDOF systems. To further demonstrate the application of the dynamic ISR method's general approach for MDOF system, a five degree of freedom (5-DOF) model was assembled in SAP2000.

As depicted in Figure 7 and Figure 8, the model contained five particles and six link supports, described using damping and stiffness parameters. By decreasing the values of the particles mass and link parameters, the post-damage model can be developed. Like the 2-DOF model, various damage types and locations can be applied to the 5-DOF model.

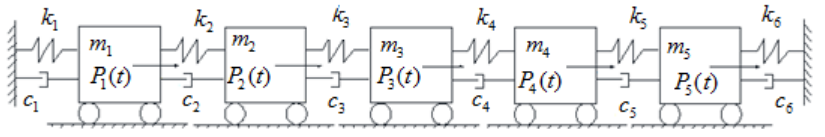

Figure 7. Five degree of freedom system model in undamaged case.

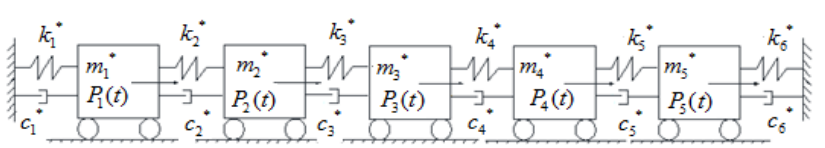

Figure 8. Five degree of freedom system model in damaged case.

To avoid repetitive simulation, only one damage case is specified, containing various mass, damping, and stiffness damages at various locations. Table 14 presents each parameter specified for the pre- and post-damaged structure, along with each of the associated theoretical damage index and severity values. The amplitudes of the applied loads $P_{1}(t), P_{2}(t), P_{3}(t), P_{4}(t), P_{5}(t)$, and $P_{6}(t)$ are chosen to be 10 kips, 9 kips, 8 kips, 7 kips, and 6 kips, respectively.

Table 14. Specified parameters for the 5-DOF damage case.

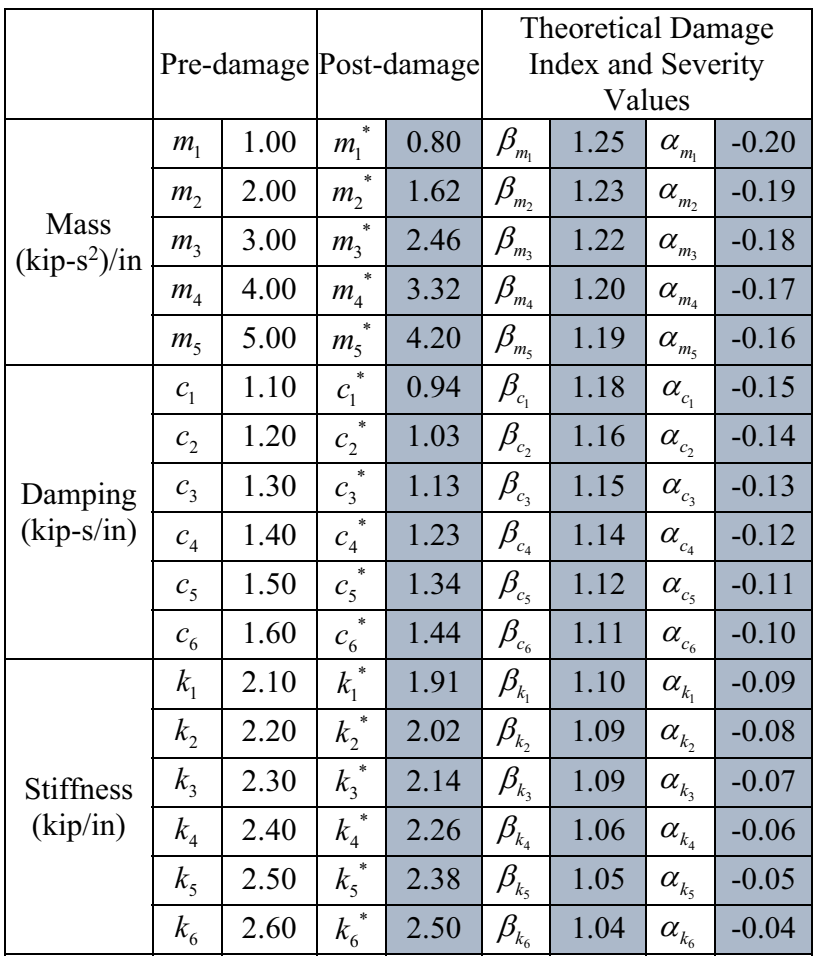

\subsection{5-DOF system results}

Unlike the 2-DOF system presented earlier, simulation for the 5-DOF system focused on a single damage case that considered various types of damage at every potential damage location. Table 15 presents the calculated values of damage indices, and Table 16 presents the corresponding damage severities. Evident from inspection of the presented tables, the results demonstrate good agreement, as indicated by the small errors between the calculated and theoretical values. 
Table 15. Damage index results for the 5-DOF case as determined using dynamic ISR.

\begin{tabular}{|c|c|c|c|c|c|c|}
\hline \multirow{2}{*}{ No. } & \multicolumn{2}{|c|}{$\beta_{m}=m / m^{*}$} & \multicolumn{2}{c|}{$\beta_{c}=c / c^{*}$} & \multicolumn{2}{c|}{$\beta_{k}=k / k^{*}$} \\
\cline { 2 - 7 } & $\begin{array}{c}\text { Calc. } \\
\text { Value }\end{array}$ & $\begin{array}{c}\text { Error } \\
(\%)\end{array}$ & $\begin{array}{c}\text { Calc. } \\
\text { Value }\end{array}$ & $\begin{array}{c}\text { Error } \\
(\%)\end{array}$ & $\begin{array}{c}\text { Calc. } \\
\text { Value }\end{array}$ & $\begin{array}{c}\text { Error } \\
(\%)\end{array}$ \\
\hline 1 & 1.25 & 0.00 & 1.18 & 0.00 & 1.10 & 0.00 \\
\hline 2 & 1.23 & 0.00 & 1.16 & 0.00 & 1.09 & 0.00 \\
\hline 3 & 1.22 & 0.00 & 1.15 & 0.00 & 1.08 & 0.00 \\
\hline 4 & 1.20 & 0.00 & 1.14 & 0.00 & 1.06 & 0.00 \\
\hline 5 & 1.19 & 0.00 & 1.12 & 0.00 & 1.05 & 0.00 \\
\hline 6 & - & - & 1.11 & 0.00 & 1.04 & 0.00 \\
\hline
\end{tabular}

Table 16. Damage severity results for the 5-DOF case as determined using dynamic ISR.

\begin{tabular}{|c|c|c|c|c|c|c|}
\hline \multirow{3}{*}{ No. } & \multicolumn{2}{|c|}{$\alpha_{m}=1 / \beta_{m}-1$} & \multicolumn{2}{c|}{$\alpha_{c}=1 / \beta_{c}-1$} & \multicolumn{2}{c|}{$\alpha_{k}=1 / \beta_{k}-1$} \\
\cline { 2 - 7 } & $\begin{array}{c}\text { Calc. } \\
\text { Value }\end{array}$ & $\begin{array}{c}\text { Abs. } \\
\text { Error }\end{array}$ & $\begin{array}{c}\text { Calc. } \\
\text { Value }\end{array}$ & $\begin{array}{c}\text { Abs. } \\
\text { Error }\end{array}$ & $\begin{array}{c}\text { Calc. } \\
\text { Value }\end{array}$ & $\begin{array}{c}\text { Abs. } \\
\text { Error }\end{array}$ \\
\hline 1 & -0.2 & $3.10 \mathrm{E}-07$ & -0.15 & $7.23 \mathrm{E}-07$ & -0.09 & $1.39 \mathrm{E}-06$ \\
\hline 2 & -0.19 & $1.53 \mathrm{E}-07$ & -0.14 & $8.90 \mathrm{E}-05$ & -0.08 & $1.94 \mathrm{E}-06$ \\
\hline 3 & -0.18 & $9.35 \mathrm{E}-09$ & -0.13 & $1.23 \mathrm{E}-07$ & -0.07 & $7.18 \mathrm{E}-08$ \\
\hline 4 & -0.17 & $1.67 \mathrm{E}-07$ & -0.12 & $1.44 \mathrm{E}-06$ & -0.06 & $9.49 \mathrm{E}-08$ \\
\hline 5 & -0.16 & $8.90 \mathrm{E}-08$ & -0.11 & $6.34 \mathrm{E}-06$ & -0.05 & $1.02 \mathrm{E}-06$ \\
\hline 6 & - & - & -0.1 & $1.29 \mathrm{E}-06$ & -0.04 & $1.55 \mathrm{E}-06$ \\
\hline
\end{tabular}

Results obtained from simulating the 5-DOF system successfully demonstrate the applicability of the proposed approach to MDOF systems. The dynamic ISR method can not only detect (identify) damage, but is also effective to locate and estimate the severity of damage(s) at various locations. The proposed methodology exhibits the superiority of a Level III non-destructive evaluation methodology for application in MDOF systems.

\subsection{Conclusions for MDOF systems}

Based on the research performed herein, the dynamic ISR method can be applied to a MDOF system for damage detection. The most direct conclusion stemming from application to MDOF systems is that the proposed dynamic ISR method can detect different damage locations and accurately determine damage severity. Implementation of the method is straight-forward, and may be implemented without knowledge of system parameters or applied loads, as experimental data alone can be used to solve the problem.

Moreover, one of the improvements in the application is that a general approach for a MDOF system was presented. According to the definition of ISR, to effectively solve the problem, the whole structural system can be divided into several component members. By performing dynamic simulations for the structural members, the experimental data can be computed from finite element programs. The proposed method can be applied to various structural systems, and is not limited to any specific model.

However, there are some limitations for the generalized approach. Comparing the percent error results for mass, damping and stiffness, it is clear that the detection error in mass is smaller compared to the error in damping and stiffness. For mass, the quantity for each member is relatively independent. As for the shared links, these errors come from the discrete dynamic analysis. But this kind of error can be slightly reduced by overlapping the results from related members.

Finally, it is also observed that the precision of results for the MDOF system is less compared to the SDOF system. Therefore, high precision sensors may still be necessary for MDOF systems.

\section{Conclusions}

This paper presented the development of the dynamic ISR method, an effective Level III NDE method to detect the existence, location and severity of damage in structures. The essential principle of this theory is that the net internal force at any given section is not impacted by the inflicted damage. The dynamic ISR method has been applied to discrete SDOF as well as MDOF systems.

The results of the dynamic ISR method demonstrate that it is possible to locate and characterize multiple damage locations accurately. Detected damages can be identified as mass, damping and stiffness damages, and the method has been demonstrated to be sensitive to detect small and inaccessible damage. No analytical model of the structure is required and only experimental data is needed to perform the analyses. The computational process is based on vibration theory, which is straight-forward and robust. The dynamic ISR method is an explicit damage identification method which can be applied to different types of structures. Future research should focus on continuous systems such as rods, beams, and frames. Moreover experimental data should be gathered to validate the proposed dynamic ISR method.

\section{Acknowledgements}

The authors would like to dedicate this paper to our esteemed co-author and friend Dr. Norris Stubbs who passed away on August 9, 2014.

\section{References}

1. J.T.P. Yao. "Concept of structural control." J Struct Div-ASCE, 98, 1567-1574 (1972)

2. C.R. Farrar, K. Worden. "An introduction to structural health monitoring." Philosophical Transactions of the Royal Society A: Mathematical." Physical and Engineering Sciences, 365, 303-315 (2007)

3. A. Rytter. "Vibration based inspection of civil engineering structures." Ph.D. dissertation, Aalborg University, Denmark (1993)

4. N. Stubbs, J.T. Kim, K. Topole. "An efficient and robust algorithm for damage localization in offshore platforms." Proc. of the ASCE Tenth Structures Congress, 543-546 (1992)

5. S. Dincal, N. Stubbs. "Damage evaluation of Timoshenko beams using invariant stress resultants." Eng Struct, 56, 2052-2064 (2013)

6. R. Li "Non-destructive evaluation based on element strain energy." M.S. Thesis, Texas A\&M University (2013) 